\title{
VIABILIDADE E ATIVIDADE ANTIOXIDANTE DE SEMENTES DE GENÓTIPOS DE FEIJÃO-MIÚDO SUBMETIDOS AO ESTRESSE SALINO ${ }^{1}$
}

\author{
CRISTIANE DEUNER ${ }^{2}$; MANOEL DE SOUZA MAIA ${ }^{3}$; SIDNEI DEUNER ${ }^{4}$; \\ ANDRÉIA DA SILVA ALMEIDA ${ }^{5}$; GÉRI EDUARDO MENEGHELLO ${ }^{6}$
}

\begin{abstract}
RESUMO - O presente trabalho teve por objetivo avaliar o efeito de diferentes concentrações salinas na germinação, produção inicial de biomassa e estresse oxidativo de quatro genótipos de feijão-miúdo de uso comum na região de São José do Norte-RS. As sementes dos genótipos Amendoim, Mosqueado, Baio e Preto foram semeadas em rolos de papel "germitest" embebido em solução de cloreto de sódio nas concentrações de zero, 50, 100, 150 e 200 mM e colocados para germinar a temperatura constante de $25^{\circ} \mathrm{C}$. Os parâmetros avaliados foram: germinação, primeira contagem de germinação, comprimento e massa seca da parte aérea e de raízes das plântulas, peroxidação de lipídios e atividade específica das enzimas antioxidantes superóxido dismutase, ascorbato peroxidase e catalase. $\mathrm{O}$ aumento da concentração de sal causou efeito negativo à germinação e primeira contagem das sementes dos quatro genótipos de feijão-miúdo a partir do tratamento com $100 \mathrm{mM}$ de sal. Quanto aos parâmetros de crescimento, a análise conjunta das curvas de regressão, mostrou haver igual tendência para os quatro genótipos, com redução expressiva no crescimento concomitante ao aumento do estresse salino. Os efeitos desse estresse também foram evidenciados pelo aumento na peroxidação de lipídios no tratamento com $200 \mathrm{mM}$ de sal, seguido pela menor capacidade antioxidante das enzimas, uma vez que, nas concentrações intermediárias de sal, as enzimas antioxidantes atuaram de forma eficiente na eliminação das espécies reativas de oxigênio (EROs), evitando o estresse oxidativo. Estes resultados permitem concluir que, nas doses intermediárias de sal, houve um bom desenvolvimento inicial para os quatro genótipos de feijão-miúdo, sendo a melhor resposta obtida no genótipo Amendoim.
\end{abstract}

Termos para indexação: Vigna unguiculata L., salinidade, germinação, crescimento e estresse oxidativo.

\section{VIABILITY AND ANTIOXIDANT ACTIVITY IN SEEDS OF COWPEA GENOTYPES SUBMITTED TO SALT STRESS}

\begin{abstract}
This study aimed to evaluate the effect of different salt concentrations on the germination, initial biomass and oxidative stress of four cowpea genotypes, commonly grown in the São José do Norte region, RS. The seeds of the genotypes Amendoim, Mosqueado,
\end{abstract}

${ }^{1}$ Submetido em 23/12/2010. Aceito para publicação em 09/05/2011.

${ }^{2}$ Eng. Agr., mestranda do Programa de PPG em Ciência e Tecnologia de Sementes, Departamento de Fitotecnia, Universidade Federal de Pelotas (UFPel), Campus Universitário S/N, 96010-900, Pelotas, RS. E-mail: cdeuner@yahoo.com.br

${ }^{3}$ Eng. Agr., Dr., Prof. Associado do Departamento de Fitotecnia da Faculdade de Agronomia Eliseu Maciel, Programa de PPG em Ciência e Tecnologia de Sementes - UFPel. Campus Universitário S/N, 96010-900, Pelotas, RS. E-mail: maiams@ufpel.edu.br

${ }^{4}$ Eng. Agr., Dr., Pesquisador Embrapa Cerrados, BR 020, km18, Cx.
Postal 08223, 73310-970, Planaltina, DF. E-mail: sidnei.deuner@cpac. embrapa.br

${ }^{5}$ Bióloga, doutoranda do Programa de PPG em Ciência e Tecnologia de Sementes, Departamento de Fitotecnia - UFPel, Campus Universitário S/N, 96010-900, Pelotas, RS. E-mail: andreiaalmeidas@hotmail.com

${ }^{6}$ Eng. Agr., Dr., Departamento de. Fitotecnia da Faculdade de Agronomia Eliseu Maciel, Programa de PPG em Ciência e Tecnologia de Sementes - UFPEL. Campus Universitário S/N, 96010-900, Pelotas, RS. E-mail: geriem@ufpel.edu.br

* Autor para correspondência. 
Baio and Preto were planted in rolls of "germitest" paper, soaked in a solution of sodium chloride at concentrations of zero, 50, 100, 150 and $200 \mathrm{mM}$ and placed to germinate at a constant temperature of $25{ }^{\circ} \mathrm{C}$. Variables studied were: germination, first count, length and dry mass of the shoots and roots of seedlings, lipid peroxidation and the specific activity of superoxide dismutase, ascorbate peroxidase and catalase. Increasing salt concentration adversely affected seed germination and also the first count of the four cowpea genotypes for the $100 \mathrm{mM}$ salt treatment. Joint analysis of the regression curves for the growth parameters showed the same tendency for the four genotypes, with a significant growth reduction as salt stress increased. Stress effects were also evident from increased lipid peroxidation in the $200 \mathrm{mM}$ salt treatment, followed by reduced enzyme antioxidant activity, since in the intermediate salt concentrations, the antioxidant enzymes efficiently eliminated reactive oxygen species (ROS), preventing oxidative stress. These results indicate that, at intermediate doses of salt, there was good initial development of the four cowpea genotypes and the best response was observed in the Amendoim genotype.

Index terms: Vigna unguiculata L., salinity, germination, growth and oxidative stress.

\section{INTRODUÇÃO}

O feijão-miúdo (Vigna unguiculata (L.) Walp), importante leguminosa anual, é encontrado em todo território nacional. No Rio Grande do Sul (RS) a maior produção encontra-se nos municípios de São José do Norte, Tavares e Mostardas, onde há pouco mais de uma década, foram identificados genótipos com elevada produção de biomassa, altamente adaptados a solos com baixa fertilidade, conforme ocorrência na planície costeira do Estado e também no nordeste brasileiro (Bevilaqua et al., 2007). Estima-se que estes genótipos tenham sido introduzidos na região com a chegada dos colonizadores açorianos, em 1725.

Nas regiões Norte e Nordeste do país, o feijão-miúdo é muito utilizado na alimentação humana. $\mathrm{Na}$ região Sul, é empregado como cobertura morta, recuperação de solos e alimentação animal (Araújo et al., 1984), especialmente pela sua importância na melhoria da qualidade e produtividade das pastagens, resultando em maior produção de carne e leite por animal, tanto em cultivo singular como em consorciação com milho ou milheto (Bevilaqua et al., 2007). Entretanto, estudos a cerca do comportamento fisiológico das sementes frente a condições adversas praticamente são inexistentes.

Há fatores ambientais, denominados estresses ou distúrbios ambientais, que limitam a produtividade agrícola (Ashraf e Harris, 2004). A salinidade é um dos mais importantes fatores de estresse abiótico, afetando diversos aspectos da fisiologia e bioquímica das plantas, reduzindo significativamente seus rendimentos. Altas concentrações exógenas de sal afetam a germinação das sementes, causando déficit hídrico e desequilíbrio iônico nas células, resultando em toxicidade e estresse osmótico (Khan e Panda, 2008). Condições de elevada salinidade podem ser causadas por diversos fatores, como práticas inadequadas de irrigação, inundação do solo pela água do mar em regiões costeiras, como também depósito de altas concentrações de cloreto de sódio $(\mathrm{NaCl})$ em regiões com recente história geológica marinha (Tester e Davenport, 2003).

O termo salino aplica-se a solos cuja condutância elétrica é maior que $4 \mathrm{mmhos} \mathrm{cm}^{-2}$ a $25^{\circ} \mathrm{C}$ (Allison et al., 1985). Enquanto plantas halófitas são capazes de crescer em solos com concentrações de sais de até $20 \%$, as glicófitas, que envolvem a maioria das plantas cultivadas, têm seu crescimento inibido em concentrações da ordem de $0,3 \%$ a $0,5 \%$. A tolerância de plantas à salinidade é variável em função do ciclo fenológico ou do seu estádio de desenvolvimento. Espécies como sorgo, milho, feijão e trigo são menos afetadas durante a fase inicial do seu ciclo (Maas et al., 1986), entretanto, outras espécies, são bastante sensíveis durante a floração e a frutificação. Desta forma, mecanismos de defesa antioxidante podem constituir-se em estratégia para aumentar a tolerância ao estresse salino (Hernández et al., 2001).

O feijão-miúdo é considerado moderadamente tolerante à salinidade, tolera a irrigação com água salina com condutividade elétrica de até $3,3 \mathrm{dS} \mathrm{m}^{-1}$ e uma condutividade elétrica do solo de 4,9 $\mathrm{dS} \mathrm{m}^{-1}$ (Ayers e Westcot, 1999), sem redução na produtividade. No entanto, esse valor limiar pode ser variável em função da existência de variabilidade genética intraespecífica em relação a essa característica, das condições climáticas da região e 
do método de irrigação utilizado (Costa et al., 2003). As concentrações de sais que restringem o crescimento do feijão variam amplamente entre as variedades, e dependem não só do tipo de sal, mas também do tempo de exposição e do seu estádio de desenvolvimento. Segundo Amador et al. (2006), o feijão-miúdo apresenta tolerância à salinidade superior à do milho, mas inferior ao trigo, cevada, beterraba açucareira e algodão.

Para os genótipos de feijão-miúdo cultivados na região sul do Brasil, há poucos estudos sobre seu comportamento em ambientes salinos. Desta forma, sua caracterização permite ampliar o conhecimento a cerca desta espécie, servindo de ferramenta para a identificação de possíveis variações que auxiliem na seleção dos genótipos mais adaptados a condição de salinidade. Estes resultados são importantes uma vez que, a espécie possui papel fundamental na economia da região de São José do NorteRS, devido ao seu cultivo ser destinado principalmente à obtenção de forragem para o rebanho leiteiro e melhoria da fertilidade do solo em áreas marginais.

Desta forma, o objetivo desta pesquisa foi avaliar o efeito de diferentes concentrações salinas na germinação, produção inicial de biomassa e respostas antioxidantes de quatro genótipos de feijão-miúdo de uso comum na região de São José do Norte-RS.

\section{MATERIAL E MÉTODOS}

O trabalho foi desenvolvido no Laboratório Didático de Análise de Sementes do Departamento de Fitotecnia, da Faculdade de Agronomia Eliseu Maciel, Universidade Federal de Pelotas (UFPel), Pelotas-RS. O material estudado foram sementes de quatro genótipos de feijão-miúdo denominados popularmente de "Amendoim, Mosqueado, Baio e Preto", produzidos na safra 2009 no município de São José do Norte-RS.

As sementes de cada genótipo foram semeadas em rolos de papel "germitest" embebido na quantidade de 2,5 vezes o seu peso inicial com solução de cloreto de sódio $(\mathrm{NaCl})$ para simular o estresse salino, nas concentrações de 50, 100, 150, $200 \mathrm{mM}$, além do tratamento controle, sem sal. Depois de estabelecidos os diferentes tratamentos, as sementes foram colocadas para germinar em germinador com temperatura constante de $25^{\circ} \mathrm{C}$.

As variáveis estudadas foram: germinação, primeira contagem de germinação, comprimento e massa seca da parte aérea e das raízes das plântulas, peroxidação de lipídios e atividade específica das enzimas antioxidantes, superóxido dismutase (SOD), ascorbato peroxidase (APX) e catalase (CAT).

Teste de germinação - conduzido com quatro repetições de 50 sementes e três repetições por tratamento. As avaliações foram realizadas aos cinco e oito dias após a semeadura, conforme as Regras para Análise de Sementes - RAS (Brasil, 2009).

Primeira contagem do teste de germinação - realizada juntamente ao teste de germinação avaliada no quinto dia após a semeadura, segundo as RAS (Brasil, 2009).

Comprimento de parte aérea e radicular - foram utilizadas três repetições de 25 sementes por tratamento, das quais mediu-se o comprimento da parte aérea e da raiz principal, no oitavo dia após a semeadura (final do teste de germinação), com auxílio de uma régua graduada ( $\mathrm{mm})$.

Massa seca das partes aérea e radicular - as mesmas plântulas utilizadas para a determinação do comprimento da parte aérea e radicular tiveram suas partes separadas e colocadas em sacos de papel para secar em estufa a $70{ }^{\circ} \mathrm{C} \pm 2$ ${ }^{\circ} \mathrm{C}$ até peso constante, quando foi determinada a massa seca. Os cotilédones foram descartados e não foram considerados na avaliação deste parâmetro.

Peroxidação de lipídios - quantificada por meio da determinação de espécies reativas ao ácido tiobarbitúrico (TBARS), conforme descrito por Buege e Aust (1978). Tecidos foliares foram macerados em $\mathrm{N}_{2}$ líquido acrescido de 20\% de PVPP e homogeneizado em ácido tricloroacético (TCA) $0,1 \%(\mathrm{p} / \mathrm{v})$. O homogeneizado foi centrifugado a $10.000 \mathrm{~g}$, por 10 minutos. Duzentos e cinqüenta microlitros do sobrenadante foram adicionados a $1 \mathrm{~mL}$ do meio de reação $(0,5 \%(\mathrm{p} / \mathrm{v})$ de ácido tiobarbitúrico (TBA) e $10 \%$ $(\mathrm{p} / \mathrm{v})$ de TCA), incubando-se, em seguida, a $95{ }^{\circ} \mathrm{C}$, por 30 minutos. A reação foi paralisada por resfriamento rápido em gelo e as leituras determinadas em espectrofotômetro, a 535 $\mathrm{nm}$ e $600 \mathrm{~nm}$. A concentração do complexo entre aldeído malônico/ácido tiobarbitúrico (MDA/TBA) foi calculada usando o coeficiente de extinção $1,55 \mathrm{mM}^{-1} \mathrm{~cm}^{-1}$.

Atividade enzimática - determinada a partir da maceração de $200 \mathrm{mg}$ de tecido vegetal na presença de $50 \%$ de polivinilpolipirolidona (PVPP) e homogeneizado em 1,8 mL do tampão de extração composto por: fosfato de potássio $100 \mathrm{mM}(\mathrm{pH} 7,8)$, EDTA $0,1 \mathrm{mM}$ e ácido ascórbico $10 \mathrm{mM}$. Após centrifugação a $12.000 \mathrm{~g}$ por 15 minutos, a $4{ }^{\circ} \mathrm{C}$, o sobrenadante foi coletado. O extrato obtido pela centrifugação foi utilizado para a quantificação das proteínas em espectrofotômetro a $595 \mathrm{~nm}$ pelo método de Bradford (1976) e determinação da atividade específica das enzimas antioxidantes, descrita a seguir. 
A atividade da SOD foi avaliada pela capacidade da enzima em inibir a fotorredução do azul de nitrotetrazólio (NBT) (Giannopolitis e Ries, 1977), em um meio de reação composto por fosfato de potássio $100 \mathrm{mM}(\mathrm{pH}$ 7,8), metionina $14 \mathrm{mM}$, EDTA $0,1 \mu \mathrm{M}$, NBT $75 \mu \mathrm{M}$ e riboflavina $2 \mu \mathrm{M}$. As leituras foram realizadas a 560 $\mathrm{nm}$. Uma unidade da SOD corresponde à quantidade de enzima capaz de inibir em $50 \%$ a fotorredução do NBT nas condições de ensaio. A atividade da APX foi determinada segundo Nakano e Asada (1981), pela avaliação da taxa de oxidação do ascorbato a $290 \mathrm{~nm}$. O meio de reação incubado a $28{ }^{\circ} \mathrm{C}$ foi composto de tampão fosfato de potássio $100 \mathrm{mM}$ (pH 7,0), ácido ascórbico 0,5 $\mathrm{mM} \mathrm{e} \mathrm{H}_{2} \mathrm{O}_{2} 0,1 \mathrm{mM}$. A atividade da CAT foi determinada conforme Azevedo et al. (1998), estimada pelo decréscimo na absorbância a $240 \mathrm{~nm}$ durante 2 min em um meio de reação contendo fosfato de potássio $100 \mathrm{mM}(\mathrm{pH} 7,0)$ e $\mathrm{H}_{2} \mathrm{O}_{2} 12,5 \mathrm{mM}$.

Os dados foram submetidos à análise de variância e regressão utlizando-se a metodologia descrita para regressão polinomial através do Programa Estatístico WinStat 1.0.

\section{RESULTADOS E DISCUSSÃO}

Analisando os dados através da análise de regressão, foi observado efeito significativo das concentrações salinas sobre a germinação e o crescimento de plântulas para os quatro genótipos de feijão-miúdo (Figura 1).
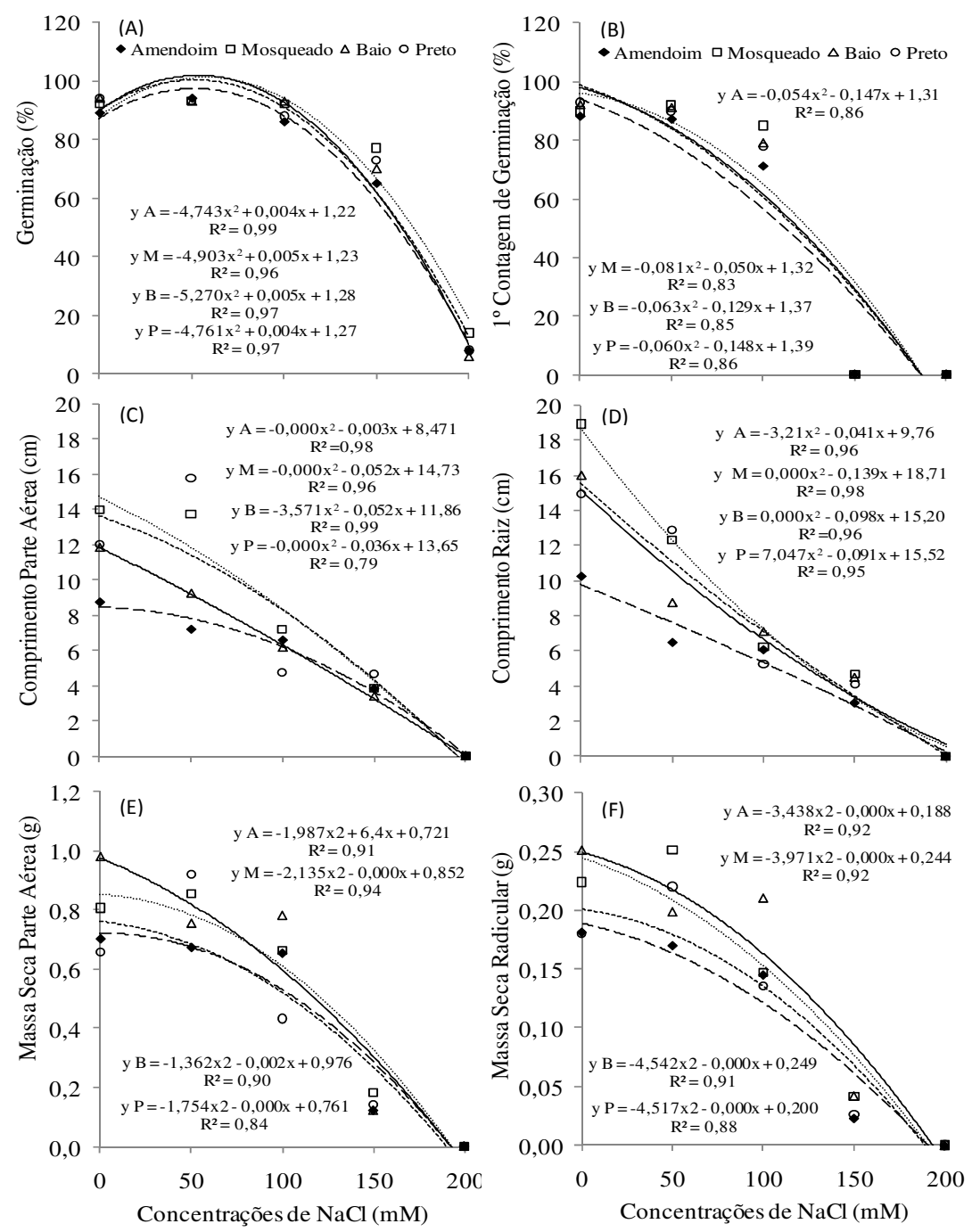

FIGURA 1. Germinação (A), primeira contagem de germinação (B), comprimento da parte aérea (C), comprimento de raiz (D), massa seca de parte aérea (E) e massa seca de raiz (F) de quatro genótipos de feijãomiúdo identificados pela letra inicial (Amendoim, Baio, Mosqueado e Preto) submetidos a diferentes concentrações de $\mathrm{NaCl}$. 
$\mathrm{Na}$ ausência de sal, os genótipos apresentaram média de germinação das sementes de 93\% (Figura 1A). Estes valores se mantiveram até a concentração de $100 \mathrm{mM}$ de $\mathrm{NaCl}$, caracterizando não haver efeito significativo dos tratamentos salinos com concentrações iguais ou inferiores a $100 \mathrm{mM}$ sobre a germinação das sementes. Por outro lado, nas concentrações mais elevadas, 150 e $200 \mathrm{mM}$ de $\mathrm{NaCl}$, houve redução gradual na germinação, chegando a valores inferiores a $10 \%$ na maior concentração testada para os genótipos Amendoim, Baio e Preto e a 15\% para o Mosqueado.

A primeira contagem do teste de germinação, avaliada cinco dias após a semeadura (Figura 1B) caracterizou o efeito do estresse salino no retardo da germinação, onde, a partir da concentração de $50 \mathrm{mM}$ de $\mathrm{NaCl}$ foi observada tendência de redução para esta variável. Desta forma, assim como na avaliação final (Figura 1A), para o tratamento controle e com $50 \mathrm{mM}$ de $\mathrm{NaCl}$ a germinação praticamente já se encontrava estabilizada, porém, nas concentrações de 150 e $200 \mathrm{mM}$ ainda não haviam sementes germinadas, demonstrando o efeito negativo do estresse salino sobre esta variável.

Resultados semelhantes foram encontrados por Moraes e Menezes (2003) em sementes de soja e por Machado et al. (2006) em sementes de feijão, confirmando a diminuição da germinação com a redução do potencial osmótico das soluções no substrato. Em arroz, Lima et al. (2005) verificaram decréscimo na germinação em todas as cultivares, em função do aumento na concentração salina, e sugeriram que a salinidade afeta o desenvolvimento de plântulas normais e diminui a viabilidade e o vigor das sementes. Para Van Der Moezel e Bell (1987), o $\mathrm{NaCl}$ afeta a germinação pelo efeito osmótico e/ou pelo efeito iônico, dificultando a absorção de água ou facilitando a penetração de íons nas células. Porém, o comportamento das plantas com relação à salinidade pode variar de acordo com o seu estádio de desenvolvimento, embora não seja claro se isto é devido à susceptibilidade à salinidade em um determinado estádio de crescimento ou ao longo do período em que a planta ficou exposta ao substrato salino, ou a interação entre esses fatores.

Analisando o comprimento da parte aérea (Figura 1C) e radicular (Figura 1D), através do ajuste das curvas de regressão para os quatro genótipos, foi observado que os mesmos apresentaram tendência semelhante frente aos tratamentos estabelecidos. Para as medidas efetuadas nas plântulas do tratamento controle, os valores observados entre os quatro genótipos apresentaram considerável diferença, porém, com a aplicação do estresse salino e o aumento das suas concentrações, houve queda constante nas variáveis comprimento de parte aérea e radicular, chegando a valores próximos entre os genótipos nas maiores concentrações de sal testadas. É importante destacar que para a concentração de $200 \mathrm{mM}$ de $\mathrm{NaCl}$, houve apenas o início da protrusão da raiz primária, não sendo, desta forma, mensurados seus parâmetros de crescimento.

Nem todas as partes da planta são igualmente afetadas pela salinidade, bem como, a adaptação ao estresse salino varia entre espécies e em um mesmo genótipo pode variar entre estádios fenológicos (Morales et al., 2001). Desta forma, os efeitos da salinidade são manifestados na redução das taxas de germinação e de crescimento, diminuição do rendimento, e, em certos casos severos, podem causar a morte generalizada das plantas (Bernardo et al., 2005). De acordo com Maas (1993), muitas culturas são susceptíveis à injúria durante a emergência no solo e durante o crescimento inicial da plântula. Uma vez estabelecidas, as plantas aumentam a tolerância durante os estádios de crescimento seguintes.

Avaliando duas cultivares de feijão-miúdo, Vita 3 e Vita 5, uma tolerante e outra sensível à salinidade, respectivamente, submetidas ao tratamento com 10 $\mathrm{mM}$ de $\mathrm{NaCl}$, Aragão et al. (2005) verificaram maior influência da salinidade na cultivar Vita 5, ocorrendo redução no crescimento das raízes, da parte aérea e na área foliar. No entanto, os conteúdos de clorofila, bem como os parâmetros de fluorescência não foram afetados. Reduções no número de folhas, área foliar, altura e diâmetro do caule também foram observadas por Lima et al. (2007) em plantas de feijão-miúdo pelo aumento da salinidade da água de irrigação.

A inibição do crescimento ocasionada pela salinidade, segundo Prisco e O'leary (1970), não é devida apenas ao efeito tóxico dos sais, mas também à seca fisiológica produzida, pois ao ocorrer aumento da concentração de sais no substrato, há diminuição do potencial osmótico e, conseqüentemente, queda no potencial hídrico, podendo afetar a cinética de absorção de água pelas sementes (efeito osmótico), como também elevar a níveis tóxicos a concentração de íons no embrião (efeito tóxico).

No presente trabalho, em resposta à redução do crescimento das plântulas, a salinidade também afetou a produção de massa seca de ambas as partes das 
plântulas para os quatro genótipos de feijão-miúdo. Com o aumento das concentrações salinas houve queda constante na produção de massa seca tanto na parte aérea (Figura 1E) quanto nas raízes (Figura 1F), assim como observado na variável comprimento das partes. Estes resultados demonstram que elevadas concentrações de sal afetam significativamente o desenvolvimento normal das plântulas de feijão-miúdo. Embora, através do ajuste das curvas de regressão, os quatro genótipos tenham apresentado a mesma tendência, é possível observar que o Amendoim tendeu a uma menor declividade das curvas para os parâmetros analisados, sendo, desta forma, o genótipo que menos foi afetado pelo efeito salino.

A sensibilidade aos diferentes níveis de estresse pode variar de genótipo para genótipo e em função do tempo de exposição ao mesmo. Durante o condicionamento osmótico ocorrem incrementos no teor de proteínas solúveis e enzimas específicas, segundo Smith e Cobb (1991), o que proporciona maior concentração de solutos, podendo resultar em crescimento mais rápido e maior acúmulo de biomassa. Porém, este comportamento é mais recorrente em concentrações salinas menores, não tóxicas, o que pode explicar a menor redução no comprimento da parte aérea e produção de massa nas concentrações mais baixas de sal para os genótipos estudados.

Quando em concentrações mais elevadas, o estresse salino provoca redução no crescimento das plântulas, a exemplo do observado para os quatro genótipos de feijãomiúdo. Este fator é atribuído à diminuição na absorção de água, seguido por hidrólise limitada de reservas alimentares a partir de tecidos de armazenamento, bem como devido à translocação deficiente das reservas alimentares dos tecidos de armazenamento para o eixo em desenvolvimento (Khan e Panda, 2008).

Em plantas de Vigna radiata doses de até $150 \mathrm{mM}$ de $\mathrm{NaCl}$ expressaram aumento de massa seca de caule, enquanto o mesmo foi observado para as folhas até a dose de $100 \mathrm{mM}$. Nas raízes o estresse salino não afetou a massa seca, destacando que as plantas deste experimento permaneceram sob efeito salino somente por 24 horas (Panda e Khan, 2009). Lima et al. (2007) observaram comportamento distinto, com decréscimo linear da massa seca da parte aérea e das raízes de feijão-miúdo, cv "Quarentinha", à medida que se aumentou a salinidade da água de irrigação, sendo as avaliações realizadas 45 dias após a semeadura, com aplicação da água salina a partir do sexto dia. Estes resultados comprovam que a condição experimental e também o estádio de desenvolvimento do vegetal, podem resultar em respostas distintas, o que pode ser minimizado e mais representativo através da indução do estresse salino desde a germinação, como foi realizado no presente trabalho.

Avaliando a tolerância de 50 genótipos de feijãomiúdo, em condições de casa de vegetação, submetidos a diferentes níveis de salinidade, Dantas et al. (2002) concluíram que, com o aumento da salinidade ocorreu redução na produção de massa seca em todos os genótipos estudados. Ainda, os mesmos autores, citam que o teor de proteínas nos grãos, em função da salinidade do solo, independe da tolerância do genótipo à salinidade na fase de crescimento. Em estudo sobre o efeito do sal no crescimento e metabolismo de feijão-miúdo, Ferreira (2005) constatou que houve redução da massa seca de raiz nas concentrações de $250 \mathrm{mM}$ e $500 \mathrm{mM}$ e de caule apenas em $500 \mathrm{mM}$.

Pesquisas com diferentes espécies também têm demonstrado o efeito negativo da salinidade sobre o crescimento das plantas, a exemplo, em pepino (Torres et al., 2000), em trigo (Duarte et al., 2006), melancia (Torres, 2007), dentre outros.

A toxicidade iônica é outro fator que pode causar redução do crescimento das plantas sob estresse salino, desencadeando danos às membranas, redução da atividade de enzimas hidrolíticas, aumento nos níveis de peroxidação de lipídios e estimular a formação de EROs (Essa, 2008).

Os danos causados pelo sal às membranas celulares, devido à peroxidação dos lipídios, estão representados pelo aumento dos níveis de malondialdeído (MDA) (Figura 2A). Os resultados mostram que todos os genótipos de feijão-miúdo apresentaram aumento significativo na peroxidação de lipídios na concentração de $200 \mathrm{mM}$ de $\mathrm{NaCl}$, sendo que, os danos foram mais expressivos nos genótipos Mosqueado, Baio e Preto, diferindo do genótipo Amendoim. Nas demais concentrações testadas, em relação ao controle, somente o genótipo Preto expressou aumento significativo com $150 \mathrm{mM}$. Isto demonstra que concentrações elevadas, como no presente caso, $200 \mathrm{mM}$ de $\mathrm{NaCl}$, podem causar danos irreversíveis as membranas celulares, afetando severamente sua funcionalidade e integridade (Edreva, 2005). Estes resultados estão de acordo com Panda e Khan (2009), onde os autores observaram aumentos na peroxidação de lipídios em Vigna radiata sob estresse salino, sendo significativo em relação ao controle nas raízes, caules e folhas para todas as doses de $\mathrm{NaCl}$ testadas (50, $100150 \mathrm{mM})$. 

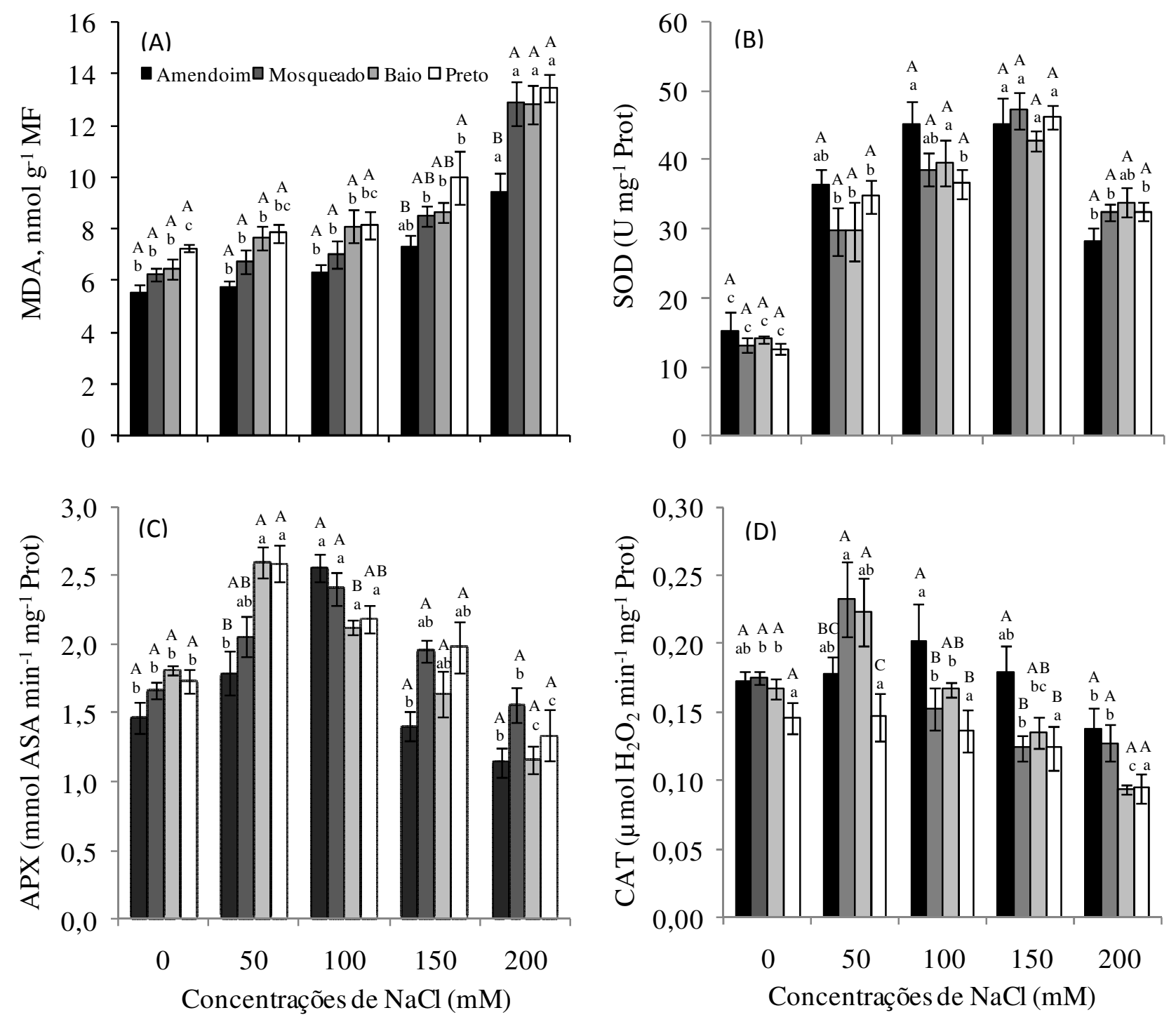

FIGURA 2. Peroxidação de lipídios (A) e atividade específica das enzimas superóxido dismutase - SOD (B), ascorbato peroxidase - APX (C) e catalase - CAT (D) em plântulas de quatro genótipos de feijão-miúdo submetidas a diferentes concentrações de $\mathrm{NaCl}$. Médias seguidas pela mesma letra maiúscula (entre genótipos) e minúscula (entre tratamentos) não diferem entre si pelo teste de Tukey $(p \leq 0,05)$.

Com o aumento do estresse, a formação de EROs é intensificada e sua eliminação deve ocorrer de forma constante para evitar o estresse oxidativo. Desta forma, a ação sincronizada das enzimas responsáveis pela remoção das EROs confere maior tolerância as plantas sob condições de estresse. A superóxido dismutase (SOD), primeira enzima a atuar no sistema antioxidante, realizando a dismutação do radical superóxido $\left(\mathrm{O}_{2}{ }^{\bullet}\right)$ a peróxido de hidrogênio $\left(\mathrm{H}_{2} \mathrm{O}_{2}\right)$, apresentou atividade significativamente superior ao controle em todas as doses de $\mathrm{NaCl}$ avaliadas (Figura 2B), caracterizando uma eficiente detoxificação das EROs, principalmente até a concentração de $150 \mathrm{mM}$ de $\mathrm{NaCl}$, onde sua atividade foi máxima. Por outro lado, a atividade da SOD entre os genótipos em cada tratamento não diferiu.

$\mathrm{O} \mathrm{H}_{2} \mathrm{O}_{2}$, gerado pela atividade da SOD também é tóxico a célula, podendo facilmente permear através das membranas, devendo ser detoxificado (Meloni et al., 2003). 
Este processo é feito pela ascorbato peroxidase (APX) e/ ou catalase (CAT), as quais pertencem a duas diferentes classes de enzimas de limpeza devido as suas diferenças na afinidade pelo $\mathrm{H}_{2} \mathrm{O}_{2}$, com a APX na ordem de $\mu \mathrm{M}$ e a CAT em mM. Assim, enquanto a APX seria responsável pela modulação refinada das EROs para a sinalização, a CAT seria responsável pela remoção do excesso de EROs gerado durante o estresse (Mittler, 2002).

Entre os quatro genótipos de feijão-miúdo estudados, foi observado comportamento distinto na atividade da APX e CAT. A atividade da APX (Figura 2C) foi significativamente superior ao controle no tratamento 50 $\mathrm{mM}$ de $\mathrm{NaCl}$ para os genótipos Baio e Preto, já em 100 $\mathrm{mM}$ de $\mathrm{NaCl}$, todos os genótipos apresentaram aumento significativo, caracterizando uma efetiva eliminação do $\mathrm{H}_{2} \mathrm{O}_{2}$ originado pela atividade da SOD (Figura 2B). Por outro lado, no tratamento com $150 \mathrm{mM}$, onde houve máxima atividade da SOD, a APX já não atuou mais de forma eficiente, sendo mais evidente no tratamento com $200 \mathrm{mM}$ de $\mathrm{NaCl}$, com atividade inferior a observada no controle. Aumentos na expressão da APX tem sido relatados em plantas submetidas a tratamentos com $\mathrm{NaCl}$ por (Kawasaki et al., 2001).

A atividade da CAT (Figura 2D), em geral, foi inferior a APX, o que é justificado pela sua menor afinidade pelo $\mathrm{H}_{2} \mathrm{O}_{2}$, tendo assim, a APX sido mais eficaz na sua remoção. Desta forma, maiores atividades da CAT foram observadas no tratamento com $50 \mathrm{mM}$ de $\mathrm{NaCl}$ para os genótipos Mosqueado e Baio e nos tratamentos com 100 e $150 \mathrm{mM}$ de $\mathrm{NaCl}$ para o Amendoim, sendo que nestas concentrações, em comparação aos demais genótipos, foi o que expressou melhor atividade.

De acordo com Zhang e Kirkham (1996), a capacidade de manutenção, em níveis elevados, da atividade da SOD, APX e CAT, sob condições de estresses ambientais, é essencial para a manutenção do equilíbrio entre a formação e a remoção do $\mathrm{H}_{2} \mathrm{O}_{2}$ do ambiente intracelular. Segundo Cakmak e Horst (1991), a redução na atividade da CAT e o aumento nas atividades das peroxidases indicam que, em plantas mantidas sob condições de estresse, o $\mathrm{H}_{2} \mathrm{O}_{2}$ gerado é mais consumido em processos oxidativos, como na peroxidação de lipídios, do que eliminado do metabolismo. A relação entre redução na atividade das enzimas antioxidantes e conseqüente maior peroxidação também foi observada por Panda e Khan (2009) em Vigna radiata sob estresse salino, havendo decréscimos na atividade da SOD em raízes, caule e folhas sob concentrações de 100 e $150 \mathrm{mM}$ de $\mathrm{NaCl}$. Esta mesma redução foi observada para a APX nas raízes, sendo que a CAT não expressou variação significativa.

De maneira geral os resultados mostram que na concentração de $200 \mathrm{mM}$ de $\mathrm{NaCl}$ houve significativa redução na atividade das enzimas antioxidantes. Comparativamente a esta resposta, houve aumento na formação de malondialdeído (MDA) através da peroxidação de lipídios (Figura 2A), o que caracterizada danos as membranas celulares, inativando as enzimas antioxidantes pelo acúmulo excessivo de EROs, levando as plântulas a não resistirem aos potencias danos oxidativos causados pela exposição ao $\mathrm{NaCl}$ (Khan e Panda, 2008). Este comportamento explica a redução na germinação e no crescimento dos genótipos de feijão-miúdo nas maiores doses de sal testadas.

\section{CONCLUSÕES}

As sementes dos quatro genótipos de feijão-miúdo mantém alta germinação até a concentração de $100 \mathrm{mM}$ de $\mathrm{NaCl}$.

O desenvolvimento das plântulas é afetado negativamente pelas maiores concentrações salinas.

Nas concentrações intermediárias de sal, as enzimas antioxidantes apresentam atividade eficiente na proteção contra o estresse salino, porém, este efeito não é mantido para a maior dose testada

A melhor resposta ao estresse salino se verifica no genótipo Amendoim, com menor peroxidação dos lipídios, resultado do menor estresse oxidativo.

\section{REFERÊNCIAS}

ALISSON, S.E.; BROWN, J.W.; HAYAWARD, H.E.; RICHARDS, L.A.; BERSNSTEIN, L.; FIREMAN, M.; PEARSON, G.A.; WILCOX, L.V.; BOWER, C.A.; HAAATCHER, J.T.; REEVE, R.C. Suelos Salinos y Sodicos. L.A. Richards, Editor, 1985. 172p.

AMADOR, B.M.; DIEGUEZ, E.T.; HERNANDEZ, J.L.G.; AGUILAR, R.L.; SERRANO, N.Y.A.; SALGADO, S. Effect of $\mathrm{NaCl}$ salinity in the genotypic variation of cowpea (Vigna unguiculata) during early vegetative growth. Scientia Horticulturae, v.108, n.4, p.423-431, 2006.

ARAGÃO, M.E.F.; GUEDES, M.M.; OTOCH, M.L.O.; GUEDES, M.I.F.; MELO,D.F.; LIMA,M.G.S.Differential responses of ribulose-1,5-bisphosphate carboxylase/ oxygenase activities of two Vigna unguiculata cultivars 
salt stress. Brazilian Journal of Plant Physiology, v.17, n.2, p.207-212, 2005.

ARAÚJO, J.P.P.de.; RIOS, G.P.; WATT, E.E.; NEVES, B.P.das; FAGERIA, N.K.; OLIVEIRA, P.de.; GUMARÃES, C.M.; SILVEIRA FILHO, A. Cultura do caupi, Vigna unguiculata (L) Walp., descrições e recomendações de cultivo. Goiânia EMBRAPA/CNPAF, 1984. 82p. (EMBRAPA-CNPAF. Circular Técnica, 18).

ASHRAF, M.; HARRIS, P.J.C. Potential biochemical indicators of salinity tolerance in plants. Plant Science, v.166, n.1, p.3-16, 2004.

AZEVEDO, R.A.; ALAS, R.M.; SMITH, R.J.; LEA, P.J. Response of antioxidant enzymes to transfer from elevated carbon dioxide to air and ozone fumigation, in the leaves and roots of wild-type and a catalase-deficient mutant of barley. Physiologia Plantarum, v.104, p.280-292, 1998.

AYERS, R.S.; WESTCOT, D.W. A qualidade da água na agricultura. Trad. GHEYI, H.R.; MEDEIROS, J.F.; DAMASCENO, F.A.V. Campina grande: UFPB, 1999. 153p. (Estudos FAO: Irrigação e Drenagem, 29).

BERNARDO, S.; SOARES, A.A.; MANTOVANI, E.C. Manual de Irrigação. $7^{\text {a }}$. Edição, Viçosa: Editora UFV, 2005. 611p.

BEVILAQUA, G.A.P.; GALHO, A.M.; ANTUNES, I.F.; MARQUES, R.L.L.; MAIA, M.S. Manejo de sistemas de produção de sementes e forragem de feijão-miúdo para a agricultura familiar. Pelotas: Embrapa Clima Temperado, 2007. 60p. (Embrapa Clima Temperado. Documentos, 204).

BRADFORD, M.M. A rapid and sensitive method for the quantitation of microgram quantities of protein utilizing the principle of protein-dye binding. Analytical Biochemistry, v.72, p.248-254, 1976.

BRASIL. Ministério da Agricultura, Pecuária e Abastecimento. Regras para análise de sementes. Ministério da Agricultura, Pecuária e Abastecimento. Secretaria de Defesa Agropecuária. Brasília, DF: Mapa/ ACS, 2009. 395p.

BUEGE, J.A.; AUST, S.D. Microsomal lipids peroxidation. Methods in Enzymology, v.52, p.302-310, 1978.

CAKMAK, I.; HORST, W.J. Effect of aluminum on lipid peroxidation, superoxide dismutase, catalase, and peroxidase activities in root tips of soybean (Glycine max). Physiologia Plantarum, v.83, p.463-468, 1991.

COSTA, P.H.A.; SILVA, J.V.; BEZERRA, M.A.; FILHO, E.J.; PRISCO, J.T.; FILHO, E.G. Crescimento e níveis de solutos orgânicos e inorgânicos em cultivares de Vigna unguiculata submetidos à salinidade. Revista Brasileira de Botânica, v.26, n.3, p.289-297, 2003.

DANTAS, J.P.; MARINHO, F.J.L.; FERREIRA, M.M.M.; AMORIM, M.S.N.; ANDRADE, S.I. O.; SALES, A.L. Avaliação de genótipos de caupi sob salinidade. Revista Brasileira de Engenharia Agrícola e Ambiental, v.6, n.3, p.425-430, 2002.

DUARTE, G.L.; LOPES, N.F.; MORAES, D.M.; SILVA, R.N. Physiological quality of wheat seeds submitted to saline stress. Revista Brasileira de Sementes, v.28, n.1, p.122-126, 2006.

EDREVA, A. The importance of non-photosynthetic pigments and cinnamic acid derivatives in photoprotection. Agriculture Ecosystems \& Environment, v.106, p.135146, 2005.

ESSA, T.A. Effect of salinity stress on growth and nutrient composition of three soybean (Glycine max L. Merrill) cultivars. Journal of Agronomy Crop Scince, v.188, p.86-93, 2008.

FERREIRA, M.A.C. Efeito do sal no metabolismo e crescimento de Vigna unguiculata L. Walp. e Vigna luteola (Jacq.) Benth. 2005. 89f. Dissertação (Mestrado em Biologia Vegetal) - Instituto de Biologia, Universidade Estadual de Campinas (UNICAMP), Campinas, 2005.

GIANNOPOLITIS, C.N.; RIES, S.K. Superoxide dismutase. I. Occurrence in higher plants. Plant Physiology, v.59, p.309-314, 1977.

HERNÁNDEZ, J.A.; FERRER, M.A.; JIMÉNEZ, A.; BARCELÓ, A.R.; SEVILLA, F. Antioxidant systems and $\mathrm{O}_{2}{ }^{-} / \mathrm{H}_{2} \mathrm{O}_{2}$ production in the apoplasto of pea leaves. Its relation with salt induced necrotic lesions in minor veins. Plant Physiology, v.127, p.817-831, 2001.

KAWASAKI, S.; BORCHERT, C.; DEYHOLOS, M.; WANG, H.; BRAZILLE, S.; KAWAI, K.; GALBRAITH, D.; BOHNERT, H. J. Gene expression profiles during the initial phase of salt stress in rice. Plant Cell, v.13, p.889905, 2001.

KHAN, M.H.; PANDA, S.K. Alterations in root lipid peroxidation and antioxidative responses in two rice cultivars under $\mathrm{NaCl}$-salinity stress. Acta Physiologiae Plantarum, v.30, n.1, p.81-89, 2008.

LIMA， M.G.S.; LOPES， N.F.; MORAES， D.M.; ABREU, C.M. Qualidade fisiológica de sementes de arroz submetidas a estresse salino. Revista Brasileira de Sementes, v.27, n.1, p.54-61, 2005. 
LIMA, C.J.G.S.; OLIVEIRA, F.A.; MEDEIROS, J.F.; OLIVEIRA, M.K.T.; ALMEIDA JÚNIOR, A. B. Resposta do feijão-caupi a salinidade da água de irrigação. Revista Verde, v.2, n.2, p.79-86, 2007.

MAAS, E.V.; POSS, J.A.; HOFFMAN, G.J. Salinity sensitivity of sorghum at three growth stages. Irrigation Science, v.7, n.1, p.1-11, 1986.

MAAS, E.V. Testing Crops for Salinity Tolerance. In: MARANVILLE, J.W. etal.(Ed.). Workshop on Adaptation of Plants to Soil Stresses INTSORMI. 1993, Nebraska. Proceedings... Lincoln: University of Nebraska, 1993. p.234-247.

MACHADO NETO, N.; CUSTÓDIO, C.C.; COSTA, P.R.; DONÁ, F.L. Deficiência hídrica induzida por diferentes agentes osmóticos na germinação e vigor de sementes de feijão. Revista Brasileira de Sementes, v.28, n.1, p.142$148,2006$.

MELONI, D.A.; OLIVA, M.A.; MARTINEZ, C.A.; CAMBRAIA, J. Photosynthesis and activity of superoxide dismutase, peroxidase and glutathione reductase in cotton under salt stress. Environmental Experimental Botany, v.49, p.69-76, 2003.

MITTLER, R. Oxidative Stress, antioxidants and stress tolerance. Trends Plant Science, v.7, p.405-410, 2002.

MORAES, G.A.F.; MENEZES, N.L. Desempenho de sementes de soja sob condições diferentes de potencial osmótico. Ciência Rural, v.33, n.2, p.219-226, 2003.

MORALES, M.A.; OLMOS, E.; TORRECILLAS, A.; ALARCON, J.J. Differences in water relations, leaf ion accumulation and excretion rates between cultivated and wild species of Limonium sp. grown in conditions of saline stress. Flora, Jena, v.196, n.5, p.345-352, 2001.
NAKANO, Y.; ASADA, K. Hydrogen peroxide is scavenged by ascobate-specific peroxidase in spinach chloroplasts. Plant Cell Physiology, v.22, n.5, p.867880, 1981.

PANDA, S.K.; KHAN, M.H. Growth, oxidative damage and antioxidant responses in greengram (Vigna radiata $\mathrm{L}$.) under short-term salinity stress and its recovery. Journal of Agronomy \& Crop Science, v.195, p.442-454, 2009.

PRISCO, J.T.; O'LEARY, J.W. Osmotic and "toxic" effects of salinity on germination of Phaseolus vulgaris L. seeds. Turrialba, v.20, n.2, p.177-184, 1970.

SMITH, P.T.; COBB, B.G. Accelerated germination of pepper seed by priming with salt solutions and water. HortScience, v.26, n.4, p.417-419, 1991.

TESTER, M.; DAVENPORT, R. $\mathrm{Na}^{+}$tolerance and $\mathrm{Na}^{+}$ transport in higher plants. Annals of Botany, v.91, n.5, p.503-527, 2003 .

TORRES, S.B.; VIEIRA, E.L.; MARCOS FILHO, J. Efeitos da salinidade na germinação e no desenvolvimento de plântulas de pepino. Revista Brasileira de Sementes, v.22, n.2, p.39-44, 2000.

TORRES, S.B. Germinação e desenvolvimento de plântulas de melancia em função da salinidade. Revista Brasileira de Sementes, v.29, n.3, p.68-72, 2007.

VAN DER MOEZEL, P.G.; BELL, D.T. The effect of salinity on the germination of some Western Australian Eucalyptus and Melaleuca species. Seed Science \& Technology, v.15, n. 1, p.239-246, 1987.

ZHANG, J.; KIRKHAM, M.B. Lipid peroxidation in sorghum and sunflower seedlings as affected by ascorbic acid, benzoic acid, and propyl gallate. Journal of Plant Physiology, v.149, n.5, p.489-493, 1996. 